\title{
Decision Model of Engineering Bid Evaluation and Its Application under Uncertain Information Environment
}

\author{
Zhili Xiong \\ School of Electronic information, Huanggang Normal University, Huanggang 438000, China \\ email: panda20052005@126.com
}

Keywords: Engineering bid evaluation; Multi-attribute decision-making; Grey correlation analysis; Interval number

\begin{abstract}
In this paper, the decision problem of engineering bid evaluation is studied, and a decision model of engineering bid evaluation is presented based on the method of grey correlation analysis. In this model, all evaluation attribute values are transformed into interval numbers, then a grey correlation degree of interval number sequence is defined to rank all alternative bids. Moreover, an engineering bid evaluation example is given to show the feasibility and effectiveness of this decision model.
\end{abstract}

\section{Introduction}

On January 1, 2000, the bidding law of the People's Republic of China was formally implemented, since then the bidding management of our country's engineering construction project marched into the legalization management track. In the legal system of bidding management, one of the important works is engineering bid assessment. The evaluation process is to select the optimal bid from all tenders. Along with the increasing standardization of bidding management, the evaluation is no longer just is the comparison of the engineering quotation, but to multiple index comprehensive evaluation for all tenders [1-5]. Therefore, how to establish a scientific evaluation method to conduct the bidding assessment work, this is an important subject related to engineering construction management [6-8].

In this paper, we study the decision problem of engineering bid evaluation, and present a decision model of engineering bid evaluation based on the method of grey correlation analysis. We try to provide a new scientific and effective quantitative method for engineering bid evaluation work in practical.

\section{Decision Model of Engineering Bid Evaluation}

The problem of engineering bid evaluation can be described as follows.

A department of construction management will organize a project bidding, and there are $m$ bidders submit bids, which denoted as $x_{1}, x_{2}, \ldots, x_{m}$. Six evaluation attributes are given to evaluate the $m$ bids, i.e., $G_{1}$ bid price (ten thousand yuan), $G_{2}$ delivery time (months), $G_{3}$ the main needed materials (ten thousand yuan), $G_{4}$ the construction plan, $G_{5}$ the quality performance and $G_{6}$ corporate reputation. The weight $w_{i}$ of attribute $G_{\mathrm{i}}$ satisfies the conditions $w_{j} \in\left[c_{j}, d_{j}\right]$, where $0 \leq c_{j} \leq d_{j} \leq 1, j=1,2, \ldots, n$, and $w_{1}+w_{2}+\ldots+w_{n}=1$. The value of attribute $G_{j}$ for bid $x_{i}$ is denoted as $a_{i j}$, and the original decision matrix is denoted as $A=\left(a_{i j}\right)_{m \times 6}$. From the information of matrix $A$, our goal is to select an optimal bidder among $m$ bidders to do this engineering project.

Now a decision model of engineering bid evaluation is presented based on the method of grey correlation analysis to solve the decision problem of engineering bid evaluation. The decision steps are given as follows.

(1) Transform all evaluation attribute values into interval numbers.

In the practical decision making, there are three types data for the above six evaluation attributes given by the decision makers, i.e., the evaluation values of $G_{1}$ and $G_{3}$ are given in the form of 
precision numbers, the evaluation values of $G_{2}$ are given in the form of interval numbers, and the evaluation values of $G_{4}, G_{5}$ and $G_{6}$ are generally in the form of linguistic fuzzy numbers such as "very good, good, common, poor, very poor" or "very high, high, common, low, very low".

For a precision number $a_{i j}$, the corresponding interval number is $\left[a_{i j}, a_{i j}\right]$.

For the linguistic fuzzy numbers such as "very good, good, common, poor, very poor" or "very high, high, common, low, very low", the method of transforming them into interval numbers are given as follows.

very good $=[80,100]$, good $=[60,80]$, common $=[40,60]$, poor $=[20,40]$, very poor $=[0,20]$;

very high $=[80,100]$, high $=[60,80]$, common $=[40,60]$, low $=[20,40]$, very low $=[0,20]$.

Based on the above transformed method, suppose that the value of $a_{i j}$ attribute $G_{j}$ on $x_{i}$ is transformed into interval number $\left[a_{i j}^{-}, a_{i j}^{+}\right], j=1,2, \ldots, 6$, then the original matrix $A$ becomes

$$
B=\left[\begin{array}{cccc}
{\left[a_{11}^{-}, a_{11}^{+}\right]} & {\left[a_{12}^{-}, a_{12}^{+}\right]} & \ldots & {\left[a_{16}^{-}, a_{16}^{+}\right]} \\
{\left[a_{21}^{-}, a_{21}^{+}\right]} & {\left[a_{22}^{-}, a_{22}^{+}\right]} & \ldots & {\left[a_{26}^{-}, a_{26}^{+}\right]} \\
\ldots & \ldots & & \ldots \\
{\left[a_{m 1}^{-}, a_{m 1}^{+}\right]} & {\left[a_{m 2}^{-}, a_{m 2}^{+}\right]} & \ldots & {\left[a_{m 6}^{-}, a_{m 6}^{+}\right]}
\end{array}\right] .
$$

(2) Transform reverse attribute into positive attribute.

The positive attribute means that the greater the value is, the better the attribute is, and the positive attribute means that the smaller the value is, the better the attribute is. Due to the attributes $G_{1}$ bid price, $G_{2}$ delivery time and $G_{3}$ the main needed materials are all positive attributes, we can use the following method to transform these reverse attributes into positive attributes, i.e.,

$$
\left[b_{i j}^{-}, b_{i j}^{+}\right]=\left[-a_{i j}^{-},-a_{i j}^{+}\right], i=1,2, \ldots, m, j=1,2,3 \text {, }
$$

and the transformed matrix is denoted as $C=\left(\left[b_{i j}^{-}, b_{i j}^{+}\right]\right)_{m \times 6}$.

(3) Standardize the transformed matrix $C$.

The standardized matrix is denoted as $R=\left[r_{i j}^{-}, r_{i j}^{+}\right]_{m \times 6}$, where

$$
\left[r_{i j}^{-}, r_{i j}^{+}\right]=\frac{\left[b_{i j}^{-}, b_{i j}^{+}\right]}{\left\|A_{j}\right\|}, \quad i=1,2, \ldots, m, j=1,2, \ldots, 6 .
$$

where $\left\|A_{j}\right\|$ is a bound norm expressed by the following formula.

$\left\|A_{j}\right\|=\max \left(\max \left(\left|a_{1 j}{ }^{-}\right|,\left|a_{1 j}{ }^{+}\right|\right), \max \left(\left|a_{2 j}{ }^{-}\right|,\left|a_{2 j}{ }^{+}\right|\right), \cdots, \max \left(\left|a_{m j}{ }^{-}\right|,\left|a_{m j}{ }^{+}\right|\right)\right) \quad j=1,2, \ldots, 6$

(4) Weight the standardized matrix $R$.

The weighted matrix is denoted as $E=\left[e_{i j}^{-}, e_{i j}^{+}\right]_{m \times 6}$, where

$\left[e_{i j}^{-}, e_{i j}^{+}\right]=\left[w_{j}, w_{j}\right] \cdot\left[r_{i j}^{-}, r_{i j}^{+}\right], i=1,2, \ldots, m, j=1,2, \ldots, 6$.

(5) Determine the reference sequence

We set

$$
\begin{aligned}
& u_{0}^{-}(j)=\max _{1 \leq i \leq N} e_{i j}^{-}, j=1,2, \ldots, n, \\
& u_{0}^{+}(j)=\max _{1 \leq i \leq N} e_{i j}^{+}, j=1,2, \ldots, n,
\end{aligned}
$$

then the reference sequence is defined as

$U_{0}=\left(\left[u_{0}^{-}(1), u_{0}^{+}(1)\right],\left[u_{0}^{-}(2), u_{0}^{+}(2)\right], \ldots,\left[u_{0}^{-}(n), u_{0}^{+}(n)\right]\right)$.

(6) Calculate the grey correlation degree between each bid sequence and the reference sequence.

We set

$$
\Delta_{i}(j)=\left|\left[u_{0}^{-}(j), u_{0}^{+}(j)\right]-\left[c_{i j}^{-}, c_{i j}^{+}\right]\right|,
$$




$$
\xi_{i}(j)=\frac{\min _{i} \min _{k} \Delta_{i}(j)+\rho \max _{i} \max _{k} \Delta_{i}(j)}{\Delta_{i}(j)+\rho \max _{i} \max _{k} \Delta_{i}(j)}
$$

where $\zeta_{i}(j)$ is the grey correlation coefficient, and $\rho=0.5$, is the discrimination. Based on the values of $\zeta_{i}(j)$, we can calculate the grey correlation degree $r_{i}$ between each bid sequence $x_{i}$ and the reference sequence $U_{0}$, the computing formula is as follows.

$$
r_{i}=\frac{1}{n} \cdot \sum_{j=1}^{6} w_{j} \xi_{i}(j), \quad i=1,2, \ldots, m .
$$

The greater the value of $r_{i}$ is, the better the bid $x_{i}$.

\section{Decision Example of Engineering Bid Evaluation}

Suppose that a department of construction management will organize a project bidding, and there are four bidders submit bids, which denoted as $x_{1}, x_{2}, \ldots, x_{4}$. Six evaluation attributes are given to evaluate the $m$ bids, i.e., $G_{1}$ bid price (ten thousand yuan), $G_{2}$ delivery time (months), $G_{3}$ the main needed materials (ten thousand yuan), $G_{4}$ the construction plan, $G_{5}$ the quality performance and $G_{6}$ corporate reputation. The weight $w_{i}$ of attribute $G_{i}$ are given in Table 1 . The value $a_{i j}$ of attribute $G_{j}$ on bid $x_{i}$ is listed in Table 1 . Now our task is to select an optimal bidder among four bidders to do this engineering project.

Table 1. The bid information

\begin{tabular}{ccccccc}
\hline & $G_{1}$ & $G_{2}$ & $G_{3}$ & $G_{4}$ & $G_{5}$ & $G_{6}$ \\
\hline$x_{1}$ & 480 & {$[12,14]$} & 192 & Very good & Good & High \\
$x_{2}$ & 490 & {$[14,16]$} & 196 & Good & Common & Common \\
$x_{3}$ & 501 & {$[13,15]$} & 204 & Good & Good & Very high \\
$x_{4}$ & 475 & {$[16,18]$} & 190 & Common & Very good & Common \\
\hline Weight & 0.3 & 0.1 & 0.1 & 0.2 & 0.1 & 0.2 \\
\hline
\end{tabular}

From the data in Table 1, the decision process based on the method given in Section 2 is given as follows.

(1) Construct the interval decision matrix $B$.

From Table 1, we can see that there three types data, i.e., the evaluation values of $G_{1}$ and $G_{3}$ are all precision numbers, the evaluation values of $G_{1}$ are interval numbers, and the evaluation values of $G_{4}, G_{5}$ and $G_{6}$ are all linguistic fuzzy numbers such as "very good, good, common, poor, very poor" or "very high, high, common, low, very low". By using the transformation method given by Section 2.2, we can get the interval decision matrix $B$ as follows.

$$
B=\left[\begin{array}{cccccc}
{[480,480]} & {[12,14]} & {[192,192]} & {[80,100]} & {[60,80]} & {[60,80]} \\
{[490,490]} & {[14,16]} & {[196,196]} & {[60,80]} & {[40,60]} & {[40,60]} \\
{[501,501]} & {[13,15]} & {[204,204]} & {[60,80]} & {[60,80]} & {[80,100]} \\
{[475,475]} & {[16,18]} & {[190,190]} & {[40,60]} & {[80,100]} & {[40,60]}
\end{array}\right] .
$$

(2) Standardize the transformed matrix $B$.

We set

$$
\begin{aligned}
& \left\|A_{1}\right\|=[501,501],\left\|A_{2}\right\|=[16,18],\left\|A_{3}\right\|=[204,204], \\
& \left\|A_{4}\right\|=[80,100],\left\|A_{5}\right\|=[80,100],\left\|A_{6}\right\|=[80,100],
\end{aligned}
$$

then we obtain the standardized matrix as 
$R=\left[\begin{array}{llllll}{[0.9581,0.9581]} & {[0.6667,0.7778]} & {[0.9412,0.9412]} & {[0.8000,1.0000]} & {[0.6000,0.8000]} & {[0.6000,0.8000]} \\ {[0.9780,0.9780]} & {[0.7778,0.8889]} & {[0.9608,0.9608]} & {[0.6000,0.8000]} & {[0.4000,0.6000]} & {[0.4000,0.6000]} \\ {[1.0000,1.0000]} & {[0.7222,0.8333]} & {[1.0000,1.0000]} & {[0.6000,0.8000]} & {[0.6000,0.8000]} & {[0.8000,1.0000]} \\ {[0.9481,0.9481]} & {[0.8889,1.0000]} & {[0.9314,0.9314]} & {[0.4000,0.6000]} & {[0.8000,1.0000]} & {[0.4000,0.6000]}\end{array}\right]$, $W=[[0.3,0.3][0.1,0.1][0.1,0.1][0.2,0.2][0.1,0.1][0.2,0.2]]$.

(3) Weight the standardized matrix $R$.

By using the weighted method given by Section 2.2, we can get the weighted matrix $E$ as

$$
E=\left[\begin{array}{l}
{[0.2874,0.2874][0.0667,0.0778][0.0941,0.0941][0.1600,0.2000][0.0600,0.0800][0.1200,0.1600]} \\
{[0.2934,0.2934][0.0778,0.0889][0.0961,0.0961][0.1200,0.1600][0.0400,0.0600][0.0800,0.1200]} \\
{[0.3000,0.3000][0.0722,0.0833][0.1000,0.1000][0.1200,0.1600][0.0600,0.0800][0.1600,0.2000]} \\
{[0.2844,0.2844][0.0889,0.1000][0.0931,0.0931][0.0800,0.1200][0.0800,0.1000][0.0800,0.1200]}
\end{array}\right]
$$

(4) Determine the reference sequence

For matrix $E$, the reference sequence $U_{0}$ is

$U_{0}=([0.3,0.3],[0.0889,0.1],[0.1,0.1],[0.16,0.2],[0.08,0.1],[0.16,0.2])$.

(5) Calculate the grey correlation degree between each bid sequence and the reference sequence.

By using the formulas (1), (2) and (3), we get the grey correlation coefficient and grey correlation degree as follows.

$$
\begin{aligned}
& \xi_{1}=(0.7608,0.6429,0.8718,1.0000,0.6667,0.5000), \\
& \xi_{2}=(0.8586,0.7826,0.9107,0.5000,0.5000,0.3333), \\
& \xi_{3}=(1.0000,0.7059,1.0000,0.5000,0.6667,1.0000), \\
& \xi_{4}=(0.7198,1.0000,0.8536,0.3333,1.0000,0.3333), \\
& r_{1}=0.740366667 \\
& r_{2}=0.647533333 \\
& r_{3}=0.8121 \\
& r_{4}=0.706666667
\end{aligned}
$$

According to the values of grey correlation degree $r_{i}$, we can get the rank order of four bids as follows.

$x_{3} \succ x_{1} \succ x_{4} \succ x_{2}$.

Thus, the winner of the bid is $x_{3}$.

\section{Conclusion}

In this paper, we study the decision problem of engineering bid evaluation, and present a decision model of engineering bid evaluation based on the method of grey correlation analysis. This decision model can meet the need of comprehensive assessment of the reasonable construction units for the related management department of engineering construction. It can objectively and accurately reflect the strength of the bidding units, and have certain comparability and unity, and it also can avoid the subjective randomness, thus provide a scientific and effective quantitative method for the engineering bid evaluation work.

\section{References}

[1] J. Chou, C. Lin, A. Pham and J. Shao: Automation in Construction Vol. 54 (2015), p. 106-115.

[2] W. Low, H. Abdul-Rahman and N. Zakaria: International Journal of Project Management Vol. 33 (2015), p. 917-931. 
[3] A. Pekuri, L. Pekuri and H. Haapasalo: Construction Innovation Vol. 15 (2015), p. 180-197.

[4] A. Leśniak, and E. Plebankiewicz: Journal of Management in Engineering Vol. 31 (2013), p. 04014032.

[5] Y. Chen, S. Zhang, L. Liu and J. Hu: Engineering, Construction and Architectural Management Vol. 22 (2015), p. 2-20.

[6] E. Plebankiewicz : International Journal of Strategic Property Management Vol. 18 (2014), p. 307-316.

[7] A. Jarkas, S. Mubarak and C. Kadri: Journal of Management in Engineering Vol. 30 (2013), p. 05014007.

[8] K. Ye, L. Shen, B. Xia and B. Li: International Journal of Project Management Vol. 32 (2014), p. 461-472. 